be of great value in the Army and Navy, as reflectors for searchlights, where the breaking of the mirror in time of action might have very serious results.

In this article it has only been possible to touch the margin of the electro-chemical industry, and only, with the exception of calcium carbide, such processes as deal with electro-metallurgy and electrolytical deposition have been dwelt upon. It is hoped in another article to draw attention to the production of nonmetallic elements, and to the manufacture of chemical products both inorganic and organic.

F. Molliwo Perkin.

\section{THE PROBLEM OF COALING AT SEA.}

WAR, at the present time, brings home to us the necessity of considering "Energy," its different forms, and their practical application. In these days, when the machinery of a battleship not only propels the vessel, but lights, ventilates, and controls the working of the heavy guns, it may be said that the ship is primarily dependent on one source of energy-Coal. A vessel short of this requisite has hitherto been compelled to fall out of line and be thus useless until she has "coaled ship," which in many cases entails several miles steaming, delay, and perhaps lost opportunities.

On this account any efficient mechanical contrivance for overcoming the difficulty of obviating the ship putting into port and enabling a full recharge of energy while cruising to be possible must be looked upon by all with interest.

In the Engineering Magazine for February is an illustrated account of a series of trials made in the United States Navy with the "Miller Conveyor" for coaling at sea, and the method may be briefly described as follows:-

The battleship to be coaled tows the collier, from which it takes the coal in loads of 840 lbs. by means of an overhead cable and suspended carriage. During the experiments two points of interest presented themselves : (I) The proper distance between the ships; (2) The way of overcoming the variation required in the length of ropes caused by the rolling and pitching. With regard to the first point it was found that with 300 feet between the ships, the collier would not follow properly, but during the rough weather trial with about 400 feet between the ships, the collier followed perfectly.

The second point caused the chief difficulty, and in $\mathrm{Mr}$. Miller's design we find the length of overhead cables mad variable, as required partly by the movement of the ships themselves, and partly by the power engine on deck. In the following table will be found information and data of the five trials made :-

\begin{tabular}{|c|c|c|c|}
\hline $\begin{array}{c}\text { Trial } \\
\text { Number }\end{array}$ & Speed & $\begin{array}{l}\text { Number of loads }\left(8_{40}\right. \\
\text { lbs.) or tons trans- } \\
\text { shipped }\end{array}$ & Remarks \\
\hline First & \multirow{6}{*}{$\begin{array}{l}\frac{n}{0} \\
\stackrel{\Xi}{5} \\
\frac{5}{b} \\
0 \\
\text { in }\end{array}$} & 9 loads only & Adjustments made \\
\hline Second. & & $\begin{array}{l}\text { I } 4 \text { tons } 5 \text { cwt. in } \\
38 \mathrm{~m} .4 \text { os. }\end{array}$ & $\begin{array}{l}\text { Work stopped through lack of } \\
\text { skill on part of operator }\end{array}$ \\
\hline \multirow[t]{2}{*}{ Third } & & 22 tons in one hour & $\begin{array}{l}\text { Work could have continued but } \\
\text { for lack of sufficient crew to } \\
\text { fill the bags }\end{array}$ \\
\hline & & Between the third and & fourth slight alterations made \\
\hline Fourth & & 75 tons in $3 \mathrm{~h} .43 \mathrm{~m}$. & $\begin{array}{l}\text { Trial lasted four hours; water } \\
\text { smooth, ground swell }\end{array}$ \\
\hline Fifth & & $\begin{array}{l}80 \text { trips made in } 8 \mathrm{om} . \\
\text { or } 30 \text { tons in Ih. } 20 \mathrm{~m} \text {. }\end{array}$ & $\begin{array}{l}\text { Could have continued indefi- } \\
\text { nitely. Board of Judges } \\
\text { satisfied. Water rough. }\end{array}$ \\
\hline
\end{tabular}

As we are informed that the battleship consumed about $3 \frac{1}{2}$ tons of coal per hour, the actual (or rather "paying") rate of coaling obtained was sixteen or seventeen tons.

The behaviour of the apparatus in rough weather was satisfactory, and the author writes, "The boats steered at firs head on to the sea, the forecastle of the battleship Massachusetts was washed at every plunge, and no coal could have been NO. I $5^{8}$, VOL $\left.6_{I}\right]$ delivered there, even if desired. The course was then changed quartering on the sea; the results were the same. Then the boats steered in the trough of the sea, and the rolling did not affect the working."

The article, which is illustrated with ten good photographs and a diagram, is certainly worthy of note, and deals with a subject which it is possible will revolutionise naval warfare in the near future.

\section{MERCURY AS A NAKED EYE OBJECT.}

R ARELY visible, and always difficult to observe satisfactorily in a telescope, this planet is yet a most attractive object to the unaided eye. Not receding to a greater distance than $28^{\circ}$ from the sun, he is, however, never above the horizon in England for a longer period than two and a quarter hours before sunrise, or for a similar interval after sunset. When an evening star in the spring months or a morning star in the autumn season, he may often be caught and watched for an hour or so, shining with a sparkling, rosy lustre, and presenting much the same aspect as a fixed star.

To secure a view of Mercury forms one of the earliest and greatest ambitions of the amateur astronomer. Among his first books there will sure to be a copy of Mitchell's "Orbs of Heaven," or Dicks's "Celestial Scenery," and on reading the statement that Copernicus never succeeded in seeing Mercury, he resolves that he will do his best to catch a glimpse of this elusive little "Messenger of the Cods." After some vain attempts he finally succeeds, and it is not too much to say that the spectacle sometimes excites and gratifies the observer more than any other subsequent event in his astronomical career. Who is there among us who does not remember the thrill of pleasure incited by the first-detection of this fugitive orb, and the conscious pride with which we realised that we had commenced our celestial work by achieving a feat which had been denied to the greatest astronomer of the sixteenth century?

But, as a matter of fact, there seems to be considerable doubt whether Copernicus ever really complained of failure to see Mercury. There is evidence to show that he never expressed himself in the manner quoted in many of our popular text-books. There may, it is true, have been some ground for the statement, but it is well known that a biographer has only to introduce a special incident of the kind alluded to, or to unduly colour some expression, and whether on doubtful evidence or not, it is liable to be copied and recopied by subsequent writers without any investigation until it becomes generally accepted as a fact. But admitting for the moment that Copernicus really failed to discern Mercury, he seems to have had very good reason for it. His residence was at Thorn, in Prussia, and through the valley near ran the River Vistula, over which were frequent fogs which obliterated objects near the horizon.

This tradition about Copernicus and Mercury has certainly, however, enhanced the interest with which the planet is re garded as a naked eye object. The beautiful white lustre of Venus-incomparably brighter than the aspect of Mercurythe stronger and steadier, yellowish light of Jupiter, or the conspicuous ruddy hue of Mars may present a more striking appearance in the sky than the twilight-veiled splendour of Mercury, but there is something about the sparkling lustre of the latter orb, hovering fugitively on the brow of the horizon, which forms an attraction peculiarly its own.

The best time to observe the planet in 1900 will be during the first eleven days of March, when his times of setting will be as follows :-

\begin{tabular}{ccccc}
\multirow{3}{*}{ March } & & & h. & m. \\
& I & $\ldots$ & 7 & IO \\
& 2 & $\ldots$ & 7 & 16 \\
& 3 & $\ldots$ & 7 & $2 \mathrm{I}$ \\
& 4 & $\ldots$ & 7 & 25 \\
& 5 & $\ldots$ & 7 & 29 \\
& 6 & $\ldots$ & 7 & 33
\end{tabular}

$\begin{array}{rccc}\text { March } 7 & \ldots & 7 & 36 \\ 8 & \ldots & 7 & 39 \\ 9 & \ldots & 7 & 41 \\ \text { IO } & \ldots & 7 & 4 \mathrm{I} \\ \text { II } & \ldots & 7 & 4 \mathrm{I}\end{array}$

During this period Venus will be a very brilliant object, situated about 2I degrees E.N.E of Mercury: The greatest elongation of the latter $\left(18^{\circ} 16^{\prime} \mathrm{E}\right.$.) will occur at II a.m. on March 8 , on which day he sets about $\mathrm{rh}$. 50m. after the sun. If the western sky is clear on March 2 at about 6 p.m. an exceptionally good opportunity will occur for detecting the planet, for he 